\title{
miRNAs regulate stem cell self-renewal and differentiation
}

\author{
Zuoren Yu ${ }^{1}$, Yuan Li ${ }^{1}$, Huimin Fan ${ }^{1}$, Zhongmin Liu ${ }^{1}{ }^{*}$ and Richard G. Pestell ${ }^{2}$ \\ 1 Research Center for Translational Medicine, Key Laboratory of Arrhythmia, East Hospital, Tongji University School of Medicine, Shanghai, China \\ ${ }^{2}$ Department of Cancer Biology, Kimmel Cancer Center, Thomas Jefferson University, Philadelphia, PA, USA
}

\section{Edited by:}

Halyna R. Shcherbata, Max Planck

Society, Germany

\section{Reviewed by:}

Halyna R. Shcherbata, Max Planck Society, Germany

Patrizia Filetici, Consiglio Nazionale

delle Ricerche, Italy

\section{*Correspondence:}

Richard G. Pestell, Department of

Cancer Biology, Kimmel Cancer

Center, Thomas Jefferson University,

233 South 10th Street, BLSB

RM 1050, Philadelphia, PA 19107, USA.

e-mail:director@kimmelcancercenter.org;

Zhongmin Liu, Research Center for

Translational Medicine, Key Laboratory

of Arrhythmia, East Hospital, Tongji

University School of Medicine, 150

Jimo Road, Shanghai 200120, China.

e-mail:zhongmin_liu@sina.com

\begin{abstract}
Stem cells undergo symmetric and asymmetric divisions to generate differentiated cells and more stem cells. The balance between self-renewal and differentiation of stem cells is controlled by transcription factors, epigenetic regulatory networks, and microRNAs (miRNAs). Herein the miRNA involvement in the regulation of stem cell self-renewal and differentiation is summarized. miRNA contribution to malignancy through regulating cancer stem cells is described. In addition, the reciprocal associations between miRNAs and epigenetic modifications in control of stem cell fate are discussed.
\end{abstract}

Keywords: stem cell, microRNA, epigenetic modification, self-renewal

\section{INTRODUCTION}

Stem cells are a small population of cells with the dual capacities for both self-renewal thereby producing more stem cells and differentiation thereby generating specialized cell types (Draper et al., 2004; Velasco-Velazquez et al., 2012). Through symmetric division, one stem cell divides into two new stem cells. Through asymmetric division, one stem cell divides into another stem cell and one differentiating cell. Stem cells have been identified from embryos and various adult tissues, as well as bone marrow and blood. Embryonic stem (ES) cells are pluripotent and give rise to diverse cell types and tissues. Autologous adult stem cell transplantation is considered as one of the most promising strategies for tissue regeneration and medical therapy (Mullenix et al., 2012).

The concept of stem cells has been extended to the cancer field by the discovery of stem-like cells within tumors, referred to as cancer stem cells (CSCs). In contrast with ES and adult stem cells, CSCs are characterized by not only self-renewal and differentiation capacities, but also the ability to form tumors when transplanted into an animal host (Rosen and Jordan, 2009). CSCs have been isolated from different solid tumors including the breast, lung, brain, and colon (Al-Haji et al., 2003; Singh et al., 2003; Rivera et al., 2011). CSCs are believed to be responsible for chemo- and/or radiation-therapy resistance of cancer. Moreover, CSCs may contribute to therapy relapse and tumor cell metastasis (Velasco-Velazquez et al., 2012; Figure 1).

Multiple signaling pathways are involved in the early cell fate decisions of ES cells, adult stem cells, and CSCs. Hormone signal transduction pathways, transcription factors, epigenetic modifications, and microRNAs (miRNAs) play important roles in regulating self-renewal and differentiation of stem cells. The epigenetic modifications include histone methylation, acetylation, phosphorylation, and DNA methylation.

miRNAs are a class of multi-functional small RNA that are single-stranded, $\sim 22 \mathrm{nt}$ in length and do not encode proteins. miRNAs regulate the stability or translational efficiency of targeted messenger RNAs through complementary interaction with the target genes. Each miRNA is predicted to target hundreds of genes. At least one-third of human mRNAs could potentially be regulated by miRNAs. miRNAs are involved in a broad range of biological processes including embryonic development, self-renewal and differentiation of stem cells, cell division and proliferation, initiation and progression of cancer, and other diseases (Sotiropoulou et al., 2009; Ye et al., 2009; Liu and Tang, 2011).

miRNAs are involved in stem cell self-renewal and differentiation by targeting components that decide stem cell fate. Following transport to the cytoplasm by Exportin-5, pre-miRNAs are processed to mature miRNAs by Dicer and its partner TBRP. Dicer-deficient mouse ES cells are defective in the capacity to self-renew or differentiate indicating the importance of mature miRNAs in ES cell self-renewal and differentiation (Kanellopoulou et al., 2005). The transcription factors OCT4, SOX2, NANOG, and KLF4 are important for the maintenance of "stemness." These "stemness" factors are able to reprogram somatic cells to a pluripotent embryonic state (Takahashi and Yamanaka, 2006; Jaenisch and Young, 2008). miRNAs regulate the expression of these "stemness" factors. miR-145 directly represses OCT4, SOX2, and KLF4, inhibiting stem cell self-renewal and inducing differentiation (Xu et al., 2009). In a regulatory feedback loop, OCT4 in turn represses miR-145 expression (Xu et al., 2009). miR-134, miR-296, and 


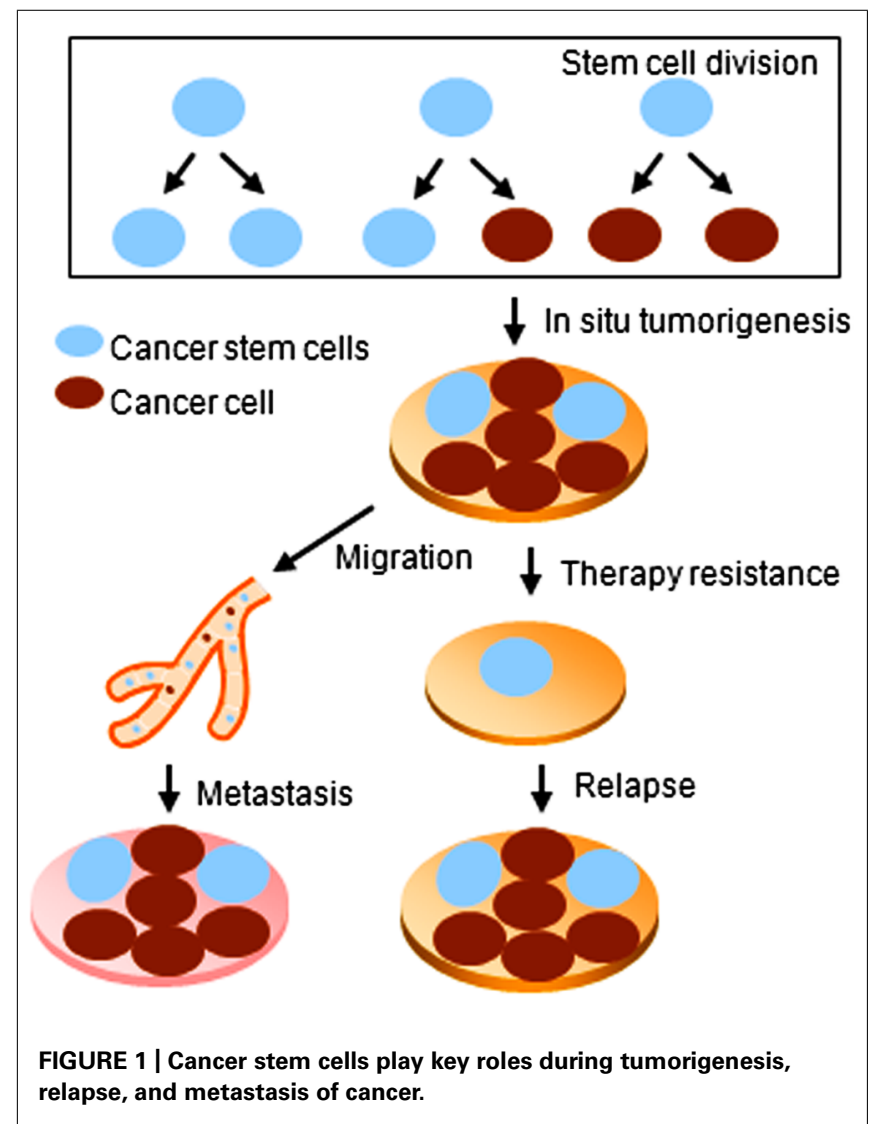

miR-470 target the coding region sequences of Nanog, Oct4, and Sox 2 genes in mouse ES cells (Tay et al., 2008). Bmi-1, a member of the Polycomb family, regulates self-renewal of stem cells by an epigenetic mechanism. Bmi-1 is activated in breast cancer stem cell (BCSC) and neural stem cell populations (Liu et al., 2006; Godlewski et al., 2008). miR-128 targets Bmi-1, suppressing CSC self-renewal and inhibiting tumorigenesis. In glioblastoma cells, Bmi-1 upregulation is associated with the downregulation of miR-128 (Godlewski et al., 2008). In addition to miR-128, miR200, miR-203, and miR-183 target Bmi-1 thereby regulating stem cells (Shimono et al., 2009).

\section{STEMNESS miRNAs}

Several miRNAs promote stem cell self-renewal. Expression of the miR-302-367 cluster is increased in stem cells, decreases after cell differentiation, and is undetectable in somatic cells. The miR302-367 cluster, which includes miR-302a/b/c/d and miR-367, was originally cloned from human and mouse ES cells. The miR302-367 cluster re-expression reprogrammed mouse and human somatic cells to a pluripotent stem cell state (Anokye-Danso et al., 2011), and reprogrammed cancer cells into an ES-like pluripotent stem cell with high expression of Oct3/4, SSEA-3, SSEA-4, Sox2, and Nanog (Lin et al., 2008). These findings suggest the miR-302367 cluster plays a role in a cellular plasticity event by promoting "stemness" of both somatic and CSCs.

The promoter of the miR-302 cluster is regulated by Oct4 and Sox 2 - two transcription factors required for stem cell maintenance (Card et al., 2008). The miR-302-362 cluster, in turn, regulates the expression of cyclin D1 and CDK4 - two fine-tuning regulators of $\mathrm{G}_{1} / \mathrm{S}$ cell cycle transition and progenitor cell function (Card et al., 2008). As such, the Oct4/Sox2-miR-302-cyclin D1 network may play an important role in maintaining the pluripotency and self-renewal properties of stem cells.

\section{DIFFERENTIATION miRNAs}

miRNAs can induce cellular differentiation by inhibiting cell cycle transition or epithelial to mesenchymal transition (EMT), inhibiting "stemness" factors either genetic (Sox2, Oct, and Nanog) or epigenetic (Bmi-1). Several miRNAs have very low level expression in stem cells which increases upon differentiation. Expression of the let-7 miRNA family is reduced in cancer (Takamizawa et al., 2004; Yu et al., 2007). let-7 expression is very low or undetectable in BCSCs, and reduced let-7 expression is required for the maintenance of "stemness." let-7 has high expression in differentiated cells. let-7 overexpression suppressed BCSC mammosphere formation and tumor formation in mice (Yu et al., 2007). After precession by Dicer and TBRP, mature miRNAs associate with Argonaute (Ago) to regulate mRNA expression through the RNA-induced silencing complex (RISC). Trim71, a target gene of let-7, associates with Argonaute 2 and miRNAs to repress Cdkn1a (p21 ${ }^{\mathrm{CIP} 1}$ ) expression, thereby inducing the $G_{1} / S$ cell cycle phase transition to promote self-renewal of ES cells (Chang et al., 2012). let-7 delivery has been used in cancer treatment in an animal model (Esquela-Kerscher et al., 2008). miR-200c also targets the Polycomb family member Bmi1. miR-200c inhibited mammary stem cell differentiation into mammary ducts and inhibited human BCSC tumor formation in vivo (Shimono et al., 2009). In breast cancer cells, miR-200 expression initiated mesenchymal to epithelial transition (MET) by targeting ZEB1 and ZEB2 (Eger et al., 2005). In glioblastoma, the aberrant cellular proliferation and self-renewal was associated with decreased expression of miR-128, which targets Bmi-1 (Godlewski et al., 2008). miR-34 inhibited tumor sphere growth and tumor formation through targeting the notch signaling pathway, which is one of the most important regulators of stem cells (Ji et al., 2009).

miRNAs involved in stem cell differentiation often show reduced abundance in cancer tissues, consistent with their role as tumor suppressors. Overexpression of these miRNAs inhibits CSC self-renewal, suggesting miRNA overexpression may be useful as a therapeutic for cancer.

\section{EPIGENETIC MODIFICATION AND MIRNA EXPRESSION}

Emerging evidence has identified feedback loops governing the epigenetic regulation of stem cells through miRNAs (Krutovskikh and Partensky, 2011; Liep et al., 2012). Histone modification and DNA methylation regulate expression of miRNAs. Similar to protein-coding genes, miRNAs are originally transcribed from genomic DNA, which may be affected by chromatin structure. Epigenetic modifications can alter chromatin folding resulting in the change of chromatin structure and thereby repressing or stimulating miRNA expression (Figure 2). Epigenetic regulation of miRNA expression has been reported in various diseases, including cancer (Saito and Jones, 2006; Lujambio et al., 2007; 


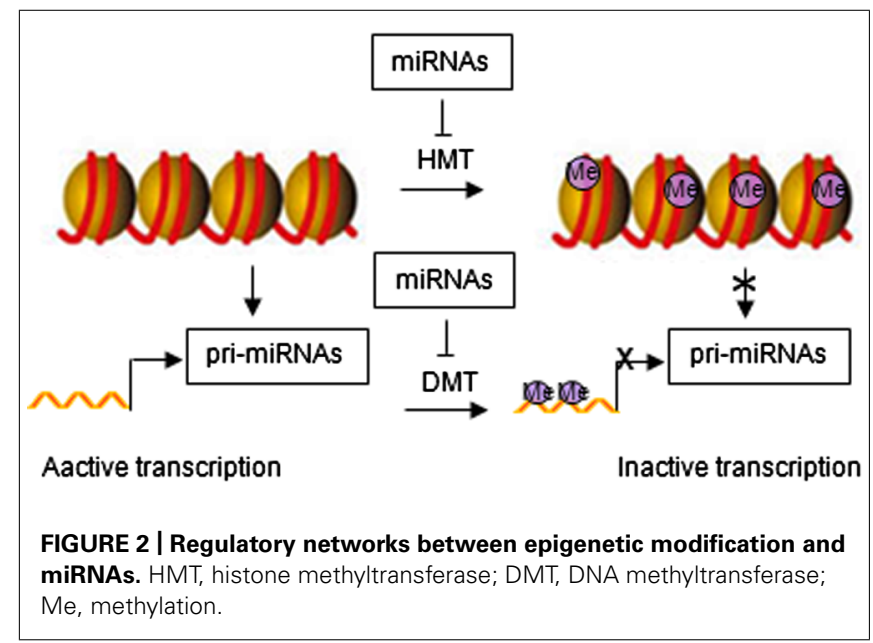

Liep et al., 2012). Epigenetic silencing of tumor suppressor miRNAs through CpG island promoter hypermethylation is emerging as a common hallmark of human tumors (Saito and Jones, 2006; Lujambio etal., 2007, 2008). For example, hypermethylationrelated silencing of miR-148a, miR-34b/c, and miR-9 in human cancer cells is associated with lymph node metastasis (Lujambio et al., 2008). miRNA-124a undergoes transcriptional inactivation by $\mathrm{CpG}$ island hypermethylation in human tumors (Lujambio et al., 2007).

miRNA in turn regulate the expression of epigenetic modifiers and transcription factors through direct target interaction and/or indirect regulation of upstream pathways (Wiklund et al., 2010, 2011). For example, miR-148 can negatively regulate DNA methyltransferase expression, resulting in hypomethylation of DNA (Braconi et al., 2010). miR-449a targets histone deacetylase-1, inhibiting the expression of histone deacetylase-1, thereby inducing growth arrest of prostate cancer cells (Noonan et al., 2009).

Through these regulatory interactions, miRNAs and epigenetic modification create a feedback and/or feedforward mechanism through which gene expression is tightly controlled (Liep et al., 2012). Aberrations in these epigenetic control systems governing miRNA expression may contribute to the development of human disease.

\section{miRNA REGULATION OF CANCER STEM CELLS}

Evidence for the function of CSCs began with human acute myeloid leukemia (AML; Lapidot et al., 1994), in which AMLinitiating cells were identified from patients on the basis of the cell surface marker $\mathrm{CD} 34^{++} \mathrm{CD} 38^{-}$expression. Upon transplantation into severe combined immune-deficient (SCID) mice, this cell population homed to the bone marrow and showed a pattern of dissemination and leukemic cell morphology similar to the original patients. Subsequently, CSCs have been identified in a variety of solid tumors, including breast, brain, colon, pancreas, lung, prostate, liver, melanoma, glioblastoma, and head and neck cancer. The CSCs have been defined by expression of distinct tissue type-specific cell surface marker including CD44, CD24, and CD133 (Al-Hajj et al., 2003; Singh et al., 2003).
Cancer stem cells undergo asymmetric cell division to maintain both a stem cell and a differentiated cancer cell population. As CSCs are often resistant to chemotherapy and/or radiationtherapy, CSCs are thought likely to contribute to tumor recurrence. miRNAs are involved in the regulation of CSC self-renewal and differentiation (Bartel, 2004; Shimono et al., 2009). A CSC-specific miRNA expression profile has been reported (Shimono etal., 2009) and altered expression of miRNAs has been identified in cancer stem/ progenitor cells which vary by tumor type (Qian et al., 2008; Shimono et al., 2009). A recent report defined distinct miRNA expression patterns in various stem/progenitor cell populations in prostate cancer, demonstrating the downregulation of tumor suppressor miRNAs including miR-34 and let-7 in prostate CSCs (Liu et al., 2012), which revealed a coordination of miRNAs in regulating CSC self-renewal and cancer cell proliferation.

\section{CONCLUDING REMARKS}

In view of the changes in miRNA abundance in a range of human diseases including cancer, miRNAs are expected to be targeted for therapy. Synthetic miRNA mimics and DNA expression vectors containing miRNA precursor sequences have strong potential as therapeutic tools. Although the therapeutic trial of miRNA mimics or expression vectors in animal models has been reported to suppress tumor growth (Esquela-Kerscher et al., 2008; Kota et al., 2009), the ideal delivery system with the characteristics of high transfection efficiency, low cellular toxicity, protection of miRNAs from degradation, and tissue-specific delivery remains a challenge. The side effects of miRNA therapy to date result from either off-target tissue effects in other organs or altered gene expression from off-target gene effects as miRNA targets multiple genes. In addition, the onco-miRNAs make them excellent targets for cancer drug treatment. Chemically modified miRNA antisense oligonucleotides have successfully inhibited target miRNA in vitro (Zhu et al., 2007) and in vivo (Garchow et al., 2011). Using this technique, a new anti-cancer approach targeting the oncogenic miRNAs is being adapted for clinical application. Interestingly, the discovery of circulating miRNA in body fluids including serum

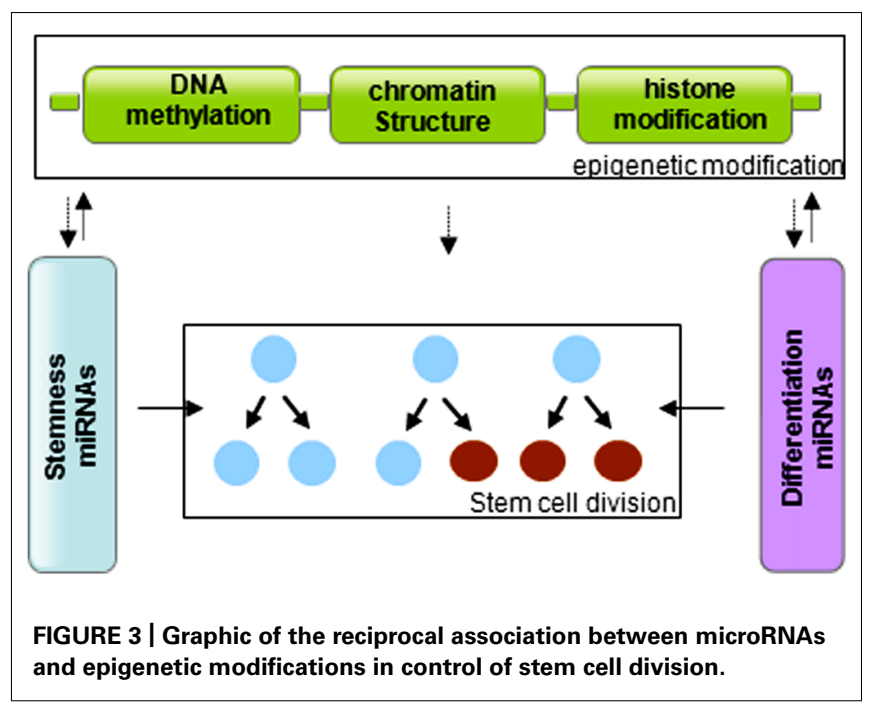


suggests miRNAs may have the potential to serve as diagnostic or prognostic biomarkers for human disease (Gilad et al., 2008; Kosaka et al., 2010).

In summary, stem cells are controlled by genetic and epigenetic regulatory networks that maintain the balance between selfrenewal and differentiation. The epigenetic regulation includes a variety of modifications that affect DNA methylation and histone modification. miRNAs regulate the stem cell characteristics through regulating the expression of transcription factors. miRNA genes are in turn subjected to epigenetic modification, and miRNAs themselves can modify chromatin structures (Figure 3). The cooperative association and reciprocal interactions between genetic and epigenetic regulatory factors and miRNAs regulate

\section{REFERENCES}

Al-Hajj, M., Wicha, M. S., BenitoHernandez, A., Morrison, S. J., and Clarke, M. F. (2003). Prospective identification of tumorigenic breast cancer cells. Proc. Natl. Acad. Sci. U.S.A. 100, 3983-3988.

Anokye-Danso, F., Trivedi, C. M., Juhr, D., Gupta, M., Cui, Z., Tian, Y., Zhang, Y., Yang, W. Gruber, P. J., Epstein, J. A., and Morrisey, E. E. (2011). Highly efficient miRNA-mediated reprogramming of mouse and human somatic cells to pluripotency. Cell Stem Cell 8 , 376-388.

Bartel, D. P. (2004). MicroRNAs: genomics, biogenesis, mechanism, and function. Cell 116, 281-297.

Braconi, C., Huang, N., and Patel, T. (2010). MicroRNA-dependent regulation of DNA methyltransferase-1 and tumor suppressor gene expression by interleukin-6 in human malignant cholangiocytes. Hepatology 51, 881-890

Card, D. A., Hebbar, P. B., Li, L., Trotter, K. W., Komatsu, Y., Mishina, Y., and Archer, T. K. (2008). Oct4/Sox2regulated miR-302 targets cyclin D1 in human embryonic stem cells. Mol. Cell. Biol. 28, 6426-6438.

Chang, H. M., Martinez, N. J., Thornton, J. E., Hagan, J. P., Nguyen, K. D., and Gregory, R. I. (2012). Trim71 cooperates with microRNAs to repress Cdknla expression and promote embryonic stem cell proliferation. Nat. Commun. 3, 923.

Draper, J. S., Moore, H. D., Ruban, L. N., Gokhale, P. J., and Andrews, P. W. (2004). Culture and characterization of human embryonic stem cells. Stem Cells Dev. 13, 325-336.

Eger, A., Aigner, K., Sonderegger, S., Dampier, B., Oehler, S., Schreiber, M., Berx, G., Cano, A., Beug, H., and Foisner, R. (2005). DeltaEF1 is a transcriptional repressor of E-cadherin and regulates epithelial plasticity in breast cancer cells. Oncogene 24, 2375-2385.
Esquela-Kerscher, A., Trang, P., Wiggins, J. F., Patrawala, L., Cheng, A., Ford, L., Weidhaas, J. B., Brown, D., Bader, A. G., and Slack, F. J. (2008). The let7 microRNA reduces tumor growth in mouse models of lung cancer. Cell Cycle 7, 759-764.

Garchow, B. G., Bartulos Encinas, O. Leung, Y. T., Tsao, P. Y., Eisenberg, R. A., Caricchio, R., Obad, S., Petri, A., Kauppinen, S., and Kiriakidou, M. (2011). Silencing of microRNA21 in vivo ameliorates autoimmune splenomegaly in lupus mice. $E M B O$ Mol. Med. 3, 605-615.

Gilad, S., Meiri, E., Yogev, Y., Benjamin, S., Lebanony, D., Yerushalmi, N., Benjamin, H., Kushnir, M., Cholakh, H., Melamed, N., Bentwich, Z. Hod, M., Goren, Y., and Chajut, A. (2008). Serum microRNAs are promising novel biomarkers. PLoS ONE 3, e3148. doi: 10.1371/journal.pone. 0003148

Godlewski, J., Nowicki, M. O., Bronisz, A., Williams, S., Otsuki, A. Nuovo, G., Raychaudhury, A., Newton, H. B., Chiocca, E. A., and Lawler S. (2008). Targeting of the Bmi-1 oncogene/stem cell renewal factor by microRNA-128 inhibits glioma proliferation and self-renewal. Cancer Res. 68, 9125-9130.

Jaenisch, R., and Young, R. (2008). Stem cells, the molecular circuitry of pluripotency and nuclear reprogram-

Ji, Q., Hao, X., Zhang, M., Tang, W., Yang, M., Li, L., Xiang, D. Desano, J. T., Bommer, G. T., Fan, D., Fearon, E. R., Lawrence, T. S., and $\mathrm{Xu}$, L. (2009). MicroRNA miR-34 inhibits human pancreatic cancer tumor-initiating cells. PLoS ONE 4, e6816. doi: 10.1371/journal.pone.0006816

Kanellopoulou, C., Muljo, S. A., Kung, A. L., Ganesan, S., Drapkin, R. Jenuwein, T., Livingston, D. M., and Rajewsky, K. (2005). Dicerdeficient mouse embryonic stem cells are defective in differentiation and ming. Cell 132, 567-582.

the self-renewal and differentiation of stem cells, and/or reprogramming of differentiated cells to induced pluripotent stem cells.

\section{ACKNOWLEDGMENTS}

This work was supported in part by grants 2012CB966800 from National Basic Research Program of China and 81172515 from Natural Science Foundation of China (to Zuoren Yu); R01CA070896, R01CA075503, R01CA132115, R01CA107382, R01CA086072 ( to Richard G. Pestell); a grant from Pennsylvania Department of Health (to Richard G. Pestell); and the Kimmel Cancer Center NIH Cancer Center Core grant P30CA056036 ( to Richard G. Pestell).

centromeric silencing. Genes Dev. 19 , 489-501.

Kosaka, N., Iguchi, H., and Ochiya, T. (2010). Circulating microRNA in body fluid: a new potential biomarker for cancer diagnosis and prognosis. Cancer Sci. 101, 2087-2092.

Kota, J., Chivukula, R. R., O’Donnell, K. A., Wentzel, E. A., Montgomery, C. L., Hwang, H. W. Chang, T. C., Vivekanandan, P., Torbenson, M., Clark, K. R., Mendell, J. R., and Mendell, J. T. (2009). Therapeutic microRNA delivery suppresses tumorigenesis in a murine liver cancer model. Cell 137, 1005-1017.

Krutovskikh, V., and Partensky, C. (2011). New insights in oncology: epigenetics and cancer stem cells. Cancer Radiother. 15, 716-722.

Lapidot, T., Sirard, C., Vormoor, J. Murdoch, B., Hoang, T., CaceresCortes, J., Minden, M., Paterson, B., Caligiuri, M. A., and Dick, J. E. (1994). A cell initiating human acute myeloid leukaemia after transplantation into SCID mice. Nature 367 645-648.

Liep, J., Rabien, A., and Jung, K. (2012). Feedback networks between microRNAs and epigenetic modification in urological tumors. Epigenetics 7 , 315-325.

Lin, S. L., Chang, D. C., Chang-Lin, S., Lin, C. H., Wu, D. T., Chen, D. T., and Ying, S. Y. (2008). Mir-302 reprograms human skin cancer cells into a pluripotent ES-cell-like state. RNA 14, 2115-2124.

Liu, C., Kelnar, K., Vlassov, A. V., Brown, D., Wang, J., and Tang, D. G. (2012). Distinct microRNA expression profiles in prostate cancer stem/progenitor cells and tumorsuppressive functions of let-7. Cancer Res. 72, 3393-3404.

Liu, C., and Tang, D. G. (2011). MicroRNA regulation of cancer stem cells. Cancer Res. 71, 5950-5954.

Liu, S., Dontu, G., Mantle, I. D., Patel, S., Ahn, N. S., Jackson, K. W., Suri, P. and Wicha, M. S. (2006). Hedgehog signaling and Bmi-1 regulate selfrenewal of normal and malignant human mammary stem cells. Cancer Res. 66, 6063-6071.

Lujambio, A., Calin, G. A., Villanueva, A., Ropero, S., Sánchez-Céspedes, M., Blanco, D., Montuenga, L. M., Rossi, S., Nicoloso, M. S., Faller, W. J., Gallagher, W. M., Eccles, S. A., Croce, C. M., and Esteller, M. (2008). A microRNA DNA methylation signature for human cancer metastasis. Proc. Natl. Acad. Sci. U.S.A. 105, 13556-13561.

Lujambio, A., Ropero, S., Ballestar, E., Fraga, M. F., Cerrato, C., Setién, F., Casado, S., SuarezGauthier, A., Sanchez-Cespedes, M., Git, A., Spiteri, I., Das, P. P., Caldas, C., Miska, E., and Esteller, M. (2007). Genetic unmasking of an epigenetically silenced microRNA in human cancer cells. Cancer Res. 67, 1424-1429.

Mullenix, P. S., Huddleston, S. J., Stojadinovic, A., Trachiotis, G. D., and Alexander, E. P. (2012). A new heart: somatic stem cells and myocardial regeneration. J. Surg. Oncol. 105, 475-480.

Noonan, E. J., Place, R. F., Pookot, D., Basak, S., Whitson, J. M., Hirata, H., Giardina, C., and Dahiya, R. (2009). miR-449a targets HDAC-1 and induces growth arrest in prostate cancer. Oncogene 28, 1714-1724.

Qian, S., Ding, J. Y., Xie, R., An, J. H., Ao, X. J., Zhao, Z. G., Sun, J. G., Duan, Y. Z., Chen, Z. T., and Zhu, B. (2008). MicroRNA expression profile of bronchioalveolar stem cells from mouse lung. Biochem. Biophys. Res. Commun. 377, 668-673.

Rivera, S., Rivera, C., Loriot, Y., Hennequin, C., Vozenin, M. C., and Deutsch, E. (2011). Cancer stem cells: a new target for lung cancer treatment. Cancer Radiother. 15, 355-364.

Rosen, J. M., and Jordan, C. T. (2009). The increasing complexity of the 
cancer stem cell paradigm. Science 324, 1670-1673.

Saito, Y., and Jones, P. A. (2006). Epigenetic activation of tumor suppressor microRNAs in human cancer cells. Cell Cycle 5, 2220-2222.

Shimono, Y., Zabala, M., Cho, R. W., Lobo, N., Dalerba, P., Qian, D., Diehn, M., Liu, H., Panula, S. P., Chiao, E., Dirbas, F. M., Somlo, G., Pera, R. A., Lao, K., and Clarke, M. F. (2009). Downregulation of miRNA200c links breast cancer stem cells with normal stem cells. Cell 138, 592-603.

Singh, S. K., Clarke, I. D., Terasaki, M., Bonn, V. E., Hawkins, C., Squire, J., and Dirks, P. B. (2003). Identification of a cancer stem cell in human brain tumors. Cancer Res. 63, 5821-5828.

Sotiropoulou, G., Pampalakis, G., Lianidou, E., and Mourelatos, Z. (2009). Emerging roles of microRNAs as molecular switches in the integrated circuit of the cancer cell. RNA 15, 1443-1461.

Takahashi, K., and Yamanaka, S. (2006). Induction of pluripotent stem cells from mouse embryonic and adult fibroblast cultures by defined factors. Cell 126, 663-676.

Takamizawa, J., Konishi, H., Yanagisawa, K., Tomida, S., Osada, H., Endoh, H., Harano, T., Yatabe, Y., Nagino, M., Nimura, Y., Mitsudomi, T., and Takahashi, T. (2004). Reduced expression of the let-7 microRNAs in human lung cancers in association with shortened postoperative survival. Cancer Res. 64, 3753-3756.

Tay, Y., Zhang, J., Thomson, A. M., Lim, B., and Rigoutsos, I. (2008). MicroRNAs to Nanog, Oct4 and Sox2 coding regions modulate embryonic stem cell differentiation. Nature 455, 1124-1128.

Velasco-Velazquez, M. A., Homsi, N., De La Fuente, M., and Pestell, R. G. (2012). Breast cancer stem cells. Int. J. Biochem. Cell Biol. 44, 573-577.

Wiklund, E. D., Gao, S., Hulf, T., Sibbritt, T., Nair, S., Costea, D. E., Villadsen, S. B., Bakholdt, V., Bramsen, J. B., Sørensen, J. A., Krogdahl, A., Clark, S. J., and Kjems, J. (2011). MicroRNA alterations and associated aberrant DNA methylation patterns across multiple sample types in oral squamous cell carcinoma. PLoS ONE 6, e27840. doi: 10.1371/journal.pone.0027840

Wiklund, E. D., Kjems, J., and Clark, S. J. (2010). Epigenetic architecture and miRNA: reciprocal regulators. Epigenomics 2, 823-840.

Xu, N., Papagiannakopoulos, T., Pan, G., Thomson, J. A., and Kosik, K. S. (2009). MicroRNA-145 regulates OCT4, SOX2, and KLF4 and represses pluripotency in human embryonic stem cells. Cell 137, 647-658.

Ye, L., Chang, J. C., Lin, C., Sun, X., Yu, J., and Kan, Y. W. (2009). Induced pluripotent stem cells offer new approach to therapy in thalassemia and sickle cell anemia and option in prenatal diagnosis in genetic diseases. Proc. Natl. Acad. Sci. U.S.A. 106, 9826-9830.

Yu, F., Yao, H., Zhu, P., Zhang, X., Pan, Q., Gong, C., Huang, Y., Hu, X., Su, F., Lieberman, J., and Song, E. (2007). let-7 regulates self renewal and tumorigenicity of breast cancer cells. Cell 131, 1109-1123.

Zhu, S., Si, M. L., Wu, H., and Mo, Y. Y. (2007). MicroRNA-21 targets the tumor suppressor gene tropomyosin
1 (TPM1). J. Biol. Chem. 282, 1432814336.

Conflict of Interest Statement: The authors declare that the research was conducted in the absence of any commercial or financial relationships that could be construed as a potential conflict of interest.

Received: 18 June 2012; accepted: 08 September 2012; published online: 25 September 2012.

Citation: Yu Z, Li Y, Fan H, Liu Z and Pestell RG (2012) miRNAs regulate stem cell self-renewal and differentiation. Front. Gene. 3:191. doi: 10.3389/ fgene.2012.00191

This article was submitted to Frontiers in Epigenomics, a specialty of Frontiers in Genetics.

Copyright (c) 2012 Yu, Li, Fan, Liu and Pestell. This is an open-access article distributed under the terms of the Creative Commons Attribution License, which permits use, distribution and reproduction in other forums, provided the original authors and source are credited and subject to any copyright notices concerning any third-party graphics etc. 